\title{
Surface, microstructural, and adhesion strength investigations of a bioactive hydroxyapatite-titanium oxide ceramic coating applied to Ti-6Al-4V alloys by plasma thermal spraying
}

\author{
Renan Carreiro Rocha ${ }^{a}$, André Gustavo de Sousa Galdino ${ }^{b *}$ 눙, Sidnei Nicodemos da Silvac ${ }^{c}$,
}

\author{
Marcelo Lucas Pereira Machado ${ }^{b}$
}

${ }^{a}$ Instituto Federal de Educação, Ciência e Tecnologia do Espirito Santo, Rua Governador José Sete, S/N, Itacibá, 29150-410, Cariacica, ES, Brasil

${ }^{b}$ Instituto Federal de Educação, Ciência e Tecnologia do Espirito Santo, Av. Vitória, 1729, Jucutuquara, 29040-780, Vitória, ES, Brasil

${ }^{c}$ Centro Federal de Educação Tecnológica de Minas Gerais, Av. Amazonas, 5253, Nova Suiça, 30421-169, Belo Horizonte, MG, Brasil

Received: December 26, 2017; Revised: March 31, 2018; Accepted: April 15, 2018

Ti-6Al-4V alloy is employed in implants because of its good mechanical strength, excellent biocompatibility, and good resistance to corrosion in biological environments. Herein, a composite (HAp- $\mathrm{TiO}_{2}, 50 \%$ by volume of both components) coating surface employing Ti-6Al-4V was characterized. Samples were analyzed post fabrication and post heat treatment to analyze the coating recrystallization, phases, crystallinity, porosity, and roughness. The coating showed rutile crystalline and amorphous Hap phases with crystallinity, porosity, and roughness of $55.6 \%, 13.6 \pm 1.0 \%$, and $4.2 \pm 0.6 \mu \mathrm{m}$; whereas, after heat treatment, it showed a rutile hydroxyapatite phase and $\beta$-TCP with values $75.6 \%, 13.9 \pm 1.9 \%$, and $3.8 \pm 0.2 \mu \mathrm{m}$, respectively. The composite exhibited $874 \pm 26$ $\mathrm{HV}_{100}$ hardness and $30 \pm 2 \mathrm{MPa}$ adhesion strength after heat treatment, which agree with previously reported data on other bioactive coatings. Therefore, this composite becomes much more crystalline after heating at $750{ }^{\circ} \mathrm{C}$ for $1 \mathrm{~h}$.

Keywords: Hydroxyapatite-titanium oxide coating, Ti-6Al-4V alloy, plasma thermal spraying, surface characterization.

\section{Introduction}

Metallic materials have been used in implants to replace or repair human body parts over the last few decades. This is mainly due to two factors: higher life expectancy and a larger number of accidents involving means of transportation and extreme sports ${ }^{1}$.

Titanium alloys have been used as implant materials because of their desirable characteristics such as a low specific mass (as compared to stainless steel and cobalt-chromium alloys), high resistance to biocorrosion, biocompatibility, and outstanding mechanical properties. Titanium and its alloys stand out among the main metallic alloys typically used in implants, mainly the alpha-beta alloys with high mechanical strength such as Ti-6Al-4V (ASTM F67 and F136 or Ti-6Al-4V ELI). These alloys are now widely used for a number of clinical applications ${ }^{2,3}$.

One of the limitations of this alloy is the potential release of $\mathrm{Al}$ and $\mathrm{V}$ ions into the human body, because these ions can eventually cause long-term health issues ${ }^{1-3}$. Recent research has focused on finding ways to prevent the release of these alloying elements and to increase the osseointegration of these metal alloys ${ }^{3-6}$. Coating these alloys with bioactive ceramics is a common practice in orthopedics and dentistry, because it combines high mechanical strength, corrosion resistance, and ease of manufacturing metal implants with enhanced biocompatibility associated with bioactive ceramic films such as hydroxyapatite (HAp) $)^{1-3}$.

Coatings are applied to metal substrates through various methods such as sol-gel ${ }^{7}$, biomimetic $^{1}$, electrolytic ${ }^{1}$, sputtering ion coating ${ }^{1}$, physical vapor deposition ${ }^{8}$, and plasma thermal spray methods ${ }^{9-11}$. The plasma spray process has the best chemical control, resistance to biocorrosion, and process efficiency among the aforementioned methods ${ }^{9-11}$.

The main concerns regarding the use of hydroxyapatite as a coating are related to substrate/coating interface instability (adhesion) and coating longevity in the physiological environment; studies have only assessed the coating efficiency over a short term (maximum of three years) ${ }^{10,12}$.

Therefore, recent studies have sought to develop bioactive ceramic coatings with improved adhesion between the coating and metal implants to thus increase the service life of implants ${ }^{6,9,10,11-14}$. 
The aim of the present study was to characterize the surface of $50 \%-50 \%$ by volume $\mathrm{HAp}-\mathrm{TiO}_{2}$ coatings applied to the Ti-6Al-4V alloy by plasma thermal spraying.

\section{Materials and Methods}

\subsection{Hydroxyapatite Powder (HAp)}

The hydroxyapatite (HAp) used in this work was kindly provided by Inside Materiais Avançados Ltda., Belo Horizonte County, Minas Gerais State, Brazil. X-ray fluorescence assays (XRF) were conducted to identify the chemical composition in the aforementioned powder. The XRF assay was performed with the Rigaku RIX 3100 X-ray fluorescence spectrometer in the Materials Engineering Department (DEMA) at the Unicamp Mechanical Engineering School (FEM) - Campinas County, São Paulo State, Brazil. The XRF assay results are presented in Table 1.

Table 1. XRF data of the as-received hydroxyapatite powder.

\begin{tabular}{cc}
\hline Chemical element & Mass quantity (\%) \\
\hline $\mathrm{O}$ & 45.428 \\
$\mathrm{Ca}$ & 37.168 \\
$\mathrm{P}$ & 17.018 \\
$\mathrm{Mg}$ & 0.131 \\
$\mathrm{Sr}$ & 0.083 \\
$\mathrm{Si}$ & 0.051 \\
$\mathrm{Al}$ & 0.045 \\
$\mathrm{Fe}$ & 0.022 \\
$\mathrm{~S}$ & 0.019 \\
$\mathrm{Na}$ & 0.017 \\
$\mathrm{~K}$ & 0.013 \\
$\mathrm{Ni}$ & 0.005 \\
\hline
\end{tabular}

The hydroxyapatite used in this work had a mean particle diameter of $8.67 \pm 0.14 \mu \mathrm{m}$ and $\mathrm{D}_{90}=17.34 \pm 0.58 \mu \mathrm{m}$.

\subsection{Titanium oxide $\left(\mathrm{TiO}_{2}\right)$}

The titanium oxide used was Metco 102 (Sulzer Metco), which was kindly provided by the Mechanical Engineering School of Unicamp. This titanium oxide is intended for plasma spraying applications, and its particle size ranges from 7.8 to $88 \mu \mathrm{m}$ (nominal value). $\mathrm{The}^{\mathrm{TiO}}{ }_{2}$ was characterized by XRF, particle size analysis, morphology, and scanning electron microscopy (SEM) prior to plasma spraying. The observed characteristics of $\mathrm{TiO}_{2}$ are presented in Table 2.

Powder granulometry is one of many variables that influences the quality of the plasma-sprayed coating due to the high heat extraction that is inherent to plasma thermal spraying. Very fine particles, of the order of $10^{6}{ }^{\circ} \mathrm{C} / \mathrm{s}$, can solidify before they touch the substrate. These particles are
Table 2. Characteristics of the titanium oxide powder (Metco 102).

\begin{tabular}{lc}
\hline Characteristic & Quantity/Quality \\
\hline $\mathrm{TiO}_{2}$ chemical composition & $99 \%$ \\
Particle size & $27.7 \pm 0.89 \mu \mathrm{m}$ (on average) \\
& $\mathrm{D}_{90}=47.97 \pm 0.41 \mu \mathrm{m}$ \\
Morphology & Angular \\
\hline
\end{tabular}

then incorporated and encapsulated by the lamellar structure of the coating after they solidify, leading to a possible drop in the adhesion strength of the coating ${ }^{11}$. Therefore, it is recommended to use powders with a particle size ranging from 20 to $100 \mu \mathrm{m}^{16}$. However, issues concerning the incorporation of solid particles by the coating can be addressed by adjusting operational variables such as the distance from the torch to the substrate, primary/secondary gas flow, and electric current in the plasma.

\subsection{Ti-6Al-4V alloy}

The Ti-6Al-4V alloy substrate was manufactured by the National Institute of Science and Technology in Biofabrication (BIOFABRIS - Brazil) by direct metal laser sintering (DMLS). The substrate had a diameter of $25.4 \mathrm{~mm}$ and height of $4.0 \mathrm{~mm}$.

The chemical composition data obtained by XRF were provided by the alloy powder supplier as well as the ASTM F136 standard (which specifies the Ti-6Al-4V composition for application in surgical implants), and are presented in Table 3 .

Table 3. Chemical composition of Ti-6Al-4V.

\begin{tabular}{lccc}
\hline \multirow{2}{*}{ Source } & \multicolumn{3}{c}{ Chemical composition (\%) } \\
\cline { 2 - 4 } & $\mathrm{Ti}$ & $\mathrm{Al}$ & $\mathrm{V}$ \\
\hline ASTM F136 & Balance & $5.5-6.75$ & $3.5-4.5$ \\
XRF & Balance & 5.9 & 4.2 \\
\hline
\end{tabular}

\subsection{Determination of the composition of the $\mathrm{HAp}-\mathrm{TiO}_{2}$ composite}

Initially, the composition $\mathrm{HAp}-\mathrm{TiO}_{2}$ was chosen because it was expected to adhere well to the metallic substrate. The ratio between $\mathrm{Hap}$ and $\mathrm{TiO}_{2}$ took into account the variation between the coefficient of thermal expansion of the coating and that of the substrate. Equations (6.8) and (6.9) by Ashby and Jones were applied for the elasticity modulus, whereas Equations [1] and [2] by Garmong and Shepard were applied for the elasticity modulus ${ }^{17}$ :

$$
\begin{aligned}
\alpha_{c u} & =f \cdot \alpha_{H A p}+f \cdot \alpha_{T i O_{2}} \\
\alpha_{c l} & =\frac{1}{\left(\frac{f}{\alpha_{H A p}}+\frac{f}{\alpha_{T i O_{2}}}\right)}
\end{aligned}
$$


where $\alpha$ is the coefficient of thermal expansion, indices $\mathrm{cu}$ and $\mathrm{cl}$ represent the upper and lower limits of the composite, $\mathrm{HAp}$ represents hydroxyapatite, $\mathrm{TiO}_{2}$ represents titanium oxide, and $f$ represents the volume fraction of the assessed material. The coefficient of thermal expansion and density of hydroxyapatite and titanium oxide are presented in Table 4.

Table 4. Thermal expansion coefficient and density of hydroxyapatite and titanium oxide.

\begin{tabular}{lcc}
\hline Material & $\begin{array}{c}\text { Coefficient of thermal } \\
\text { expansion }\left({ }^{\circ} \mathrm{C}^{-1}\right)\end{array}$ & $\begin{array}{c}\text { Specific gravity } \\
\left(\mathrm{g} / \mathrm{cm}^{3}\right)\end{array}$ \\
\hline Ti-6Al-4V & $9.2 .10^{-6}[18]$ & $4.43[18]$ \\
$\mathrm{TiO}_{2}$ rutile & $7.1 .10^{-6}[19]$ & $4.20[20]$ \\
$\mathrm{HAp}$ & $11.10^{-6}[21]$ & $3.16[21]$ \\
\hline
\end{tabular}

\subsection{Thermal plasma spraying process}

The $\mathrm{HAp}-\mathrm{TiO}_{2}$ composite was mixed by tumbling. Prior to coating, the substrate specimens were prepared by grinding with coarse alumina $\left(\mathrm{Al}_{2} \mathrm{O}_{3}\right)$ particles (grain size of 60 mesh at $75 \mathrm{psi}$ pressure, $90^{\circ}$ angle, and grinding time $30 \mathrm{~s}$ ) in order to improve substrate roughness, eliminate possible oxides that can influence coating adhesion, and facilitate mechanical anchoring of the $\mathrm{HAp}-\mathrm{TiO}_{2}$ composite. The specimens were cleaned with compressed air after blasting to remove loose alumina from the blasted surface and to prepare them for thermal spraying.

The composite was sprayed onto the Ti-6Al-4V substrate using a plasma thermal spray gun (9MBII METCO), and the coatings were manually applied in passes. This pistol model used herein has a radial dust feed, works at low to medium power levels, which can reach a maximum of $40 \mathrm{~kW}(500 \mathrm{~A}$ and $80 \mathrm{~V})$. The operational deposition conditions that were used are presented in Table 5. After the aspersion thermal process, some samples underwent heat treatment at $750{ }^{\circ} \mathrm{C}$ for one hour, in order to recrystallize and release stress.

Table 5. Parameters in the thermal plasma spray process.

\begin{tabular}{lc}
\hline Variable & Value \\
\hline Current (A) & 400 \\
Voltage (V) & 74 \\
$\mathrm{H}_{2}$ flow (L/min) & 18 \\
Air flow (L/min) & 90 \\
Powder flow g/min (L/min) & 10 \\
Gun to substrate distance (mm) & 150 \\
\hline
\end{tabular}

\subsection{Coating characterization}

Optical microscopy (OM), SEM, and X-ray diffraction (XRD) were used to characterize the coating. Samples were prepared by sanding, polishing, and etching, as well as sanding with silicon carbide $(\mathrm{SiC})$ meshes with granulates ranging from 220 to 1200 . Next, mechanical polishing was performed using a nylon cloth soaked in $1 \mu \mathrm{m}$ granulation diamond paste, followed by washing with acetone in an ultrasonic bath for $20 \mathrm{~min}$. Finally, the Keller's reaction was performed. The diffractograms presented herein were collected with a voltage of $40 \mathrm{kV}$ and a current of $10 \mathrm{~mA}$ in steps of $0.05^{\circ}$ over an observation range of $20^{\circ} \leq 2 \theta \leq 90^{\circ}$.

The crystallinity of the deposited coatings was assessed with Difract Suite Eva ${ }^{\circledR} 2010$ software, version 1.3, which automatically calculated the crystallinity by simply selecting the boundary between the typical broad peak of an amorphous pattern and the discrete diffraction peaks. The crystallinity index that was calculated by the software is based on Equation (3), wherein $\mathrm{A}_{\text {cris }}$ is the area of the crystalline peaks of the coating, because the XRD background represents the amorphous pattern area.

$$
I_{c}=\left(\frac{A_{\text {cris }}}{A_{\text {cris }}+A_{\text {amor }}}\right) \cdot 100 \%
$$

The coating roughness and porosity were evaluated to assess the physical properties of the coating. Porosity images were recorded with $\mathrm{OM}$ and captured with a digital camera coupled to the microscope. Next, these images were edited in the Adobe Photoshop ${ }^{\circledR}$ CS2 software to increase the contrast between the coating and pores. The porosity was assessed with a GSA (Semi-Automatic Granulometer) Image Analyzer. This software operates by counting pores at the intersection of lines that are pre-established by the analyzer.

\subsection{Hardness tests}

Coating hardness was assessed with the micro-hardness method according to the Vickers scale. A Shimadzu hardness tester, model HMV-2000, was used for the analysis at a 100-g load for $15 \mathrm{~s}$. Five measurements were performed per sample, and the mean coating hardness of these measurements was considered.

\subsection{Adhesion tests}

The adhesion test was performed according to the ASTM C633-08 standard. Ten cylindrical specimens with a diameter of $25.4 \mathrm{~mm}$ and a length of $25.4 \mathrm{~mm}$, as well as a self-aligning device, were produced. The self-aligning device had two degrees of freedom in order to avoid shear stress during the test. The device shown in Figure 1 was manufactured according to ASTM C633-08 recommendations. High-adhesion Scotch-Weld 2214 3M epoxy resin was used to bond the two metallic cylindrical pieces.

The set was drawn into an EMIC conventional tensile testing machine with a $100 \mathrm{kN}$ capacity. A $100 \mathrm{kN}$ load cell was used in the study and the deformation rate was found to be $0.02 \mathrm{~mm} / \mathrm{s}$. 


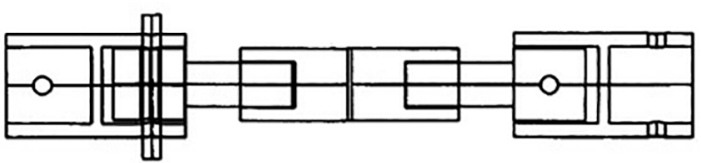

Figure 1. Fixing device used in the adhesion test. Adapted from ASTM C633-08.

\section{Results and Discussion}

\subsection{Determination of volumetric composition of the composite}

The plot in Figure 2 illustrates the influence of titanium oxide addition on the thermal expansion coefficient of the formed composite by applying the values shown in Table 3 to Equations (1) and (2).

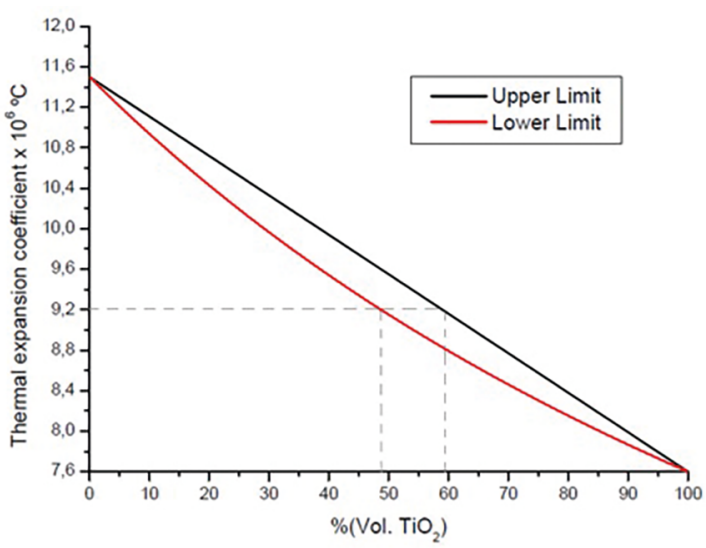

Figure 2. Influence of $\mathrm{TiO}_{2}$ on the thermal expansion coefficient of the $\mathrm{HAp}-\mathrm{TiO}_{2}$ composite.

Figure 2 shows that the addition of titanium oxide to hydroxyapatite reduced the thermal expansion coefficient of the formed composite. The range of $\mathrm{TiO}_{2}$ volume varied from $47 \%$ to $57 \%$ near the thermal expansion coefficient of the substrate (Ti-6Al-4V), which was $9 \cdot 2 \cdot 10^{-6}{ }^{\circ} \mathrm{C}^{-1}$. A composition with a higher volumetric fraction of hydroxyapatite was chosen for better composite biocompatibility and lesser difference in thermal expansion between the substrate and coating. This is because hydroxyapatite is a bio-active material whereas titanium oxide is bioinert ${ }^{14,22}$.

\subsection{Characterization of ceramic powder before deposition}

Figure 3 shows the morphology of the ceramic powders used in the present study, which exhibits granulometric dispersion as well as natural agglomeration of the particles. Pawlowski ${ }^{23}$ emphasized the importance of assessing the powders through SEM, since information about particle agglomeration is not recorded in the laser light scattering (LLS) process; accordingly, the two trials were performed.
Titanium oxide, on the other hand, had an angular morphology with a well-defined shape and size.

\subsection{Microstructural assessment and coating crystallinity}

Microscopical analysis of the coatings formed through thermal spraying allowed for verification of several important structural features such as thickness and coating adhesion to the substrate. The thickness of the deposited coating was uniform and observed to be $66.7 \pm 1.8 \mu \mathrm{m}$.

Complete overlap between the parts was observed in the substrate-coating interaction, without voids or cracks on the interface. There were fine lines parallel to the substrate in the structure, which indicates that the coating was formed by lamellar deposition, and also signifies the possible presence of diffusion processes that resulted in better coating adhesion (Figure 4 (a)).

Figure 4 (b) shows the microstructure formed by the flattened, solidified $\mathrm{HAp}-\mathrm{TiO}_{2}$ droplets which were arranged in successive layers forming the coating. It also shows the addition of well-scattered lamellae, which suggests a higher composite plasticity state at the moment they reach the surface. The mechanism responsible for film formation is triggered by the accumulation of successive layers of bioceramic powder droplets that existed in the plasma torch environment. Finally, these droplets were launched against the substrate (at a speed in excess of $400 \mathrm{~m} / \mathrm{s}$ ) which resulted in the liquid coating. The coating was flattened and experienced partial elastic recoil at the moment of impact, subsequently solidifying to form the lamellar microstructure ${ }^{15}$.

The coating phases are shown in Figure 5 (a). Only peaks characteristic of the high-crystallinity rutile phase were observed before heat treatment. There were no expected Hap peaks or peaks in phases derived from hydroxyapatite decomposition. Amorphous poplars at angles $29^{\circ}, 32^{\circ}, 33^{\circ}$, $34^{\circ}$, and $39^{\circ}$ were observed, and these angles correspond with the angles where Hap peaks are expected; this indicates a low crystallinity index in the Hap portion of the composite.

The distinct behavior that was observed in the two ceramics after the thermal process in relation to crystallinity seems to be associated with the difference in the lattice parameter of the HA phase $(\mathrm{a}=9.4 \AA)$, which was significantly higher than that of $\mathrm{TiO}_{2}(4.6 \AA)$. Since $\mathrm{TiO}_{2}$ has lower network parameter, it also has a lower tendency than HAp to become amorphous, due to the higher network parameter of HAp as compared with that of titanium oxide.

However, in addition to $\beta$-TCP formation and the presence of rutile, hydroxyapatite recrystallization was observed after the thermal treatment (Figure 4 (b)). No phase was formed from the reaction between $\mathrm{HAp}$ and $\mathrm{TiO}_{2}$.

Thus, there was a greater amount of the amorphous phase after deposition without heat treatment. In quantitative terms, the crystallinity under the deposited condition was $55.6 \%$, whereas that after heat treatment was $75.6 \%$. 


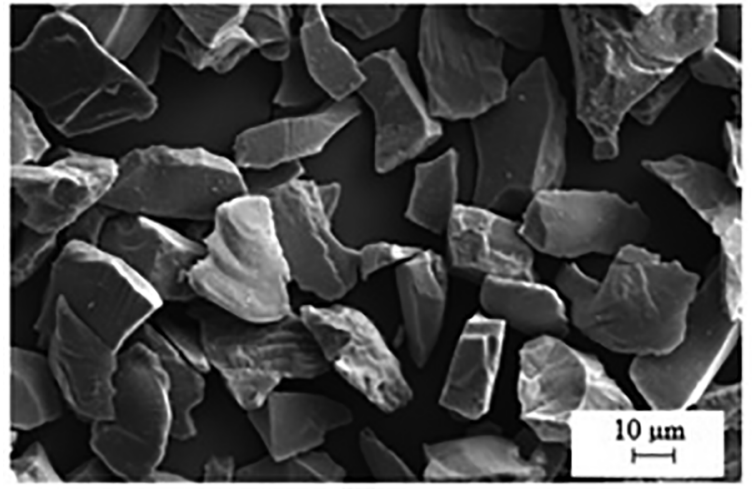

(a)

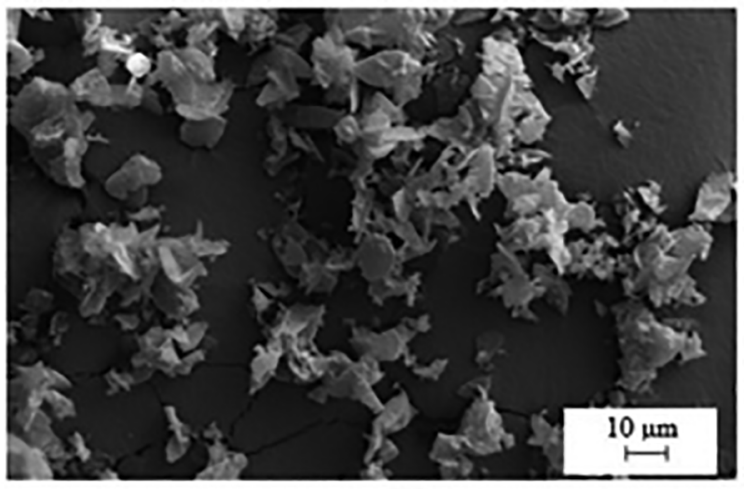

(b)

Figure 3. Ceramic morphology assessment. (a) Titanium oxide powder; and (b) Hydroxyapatite powder.

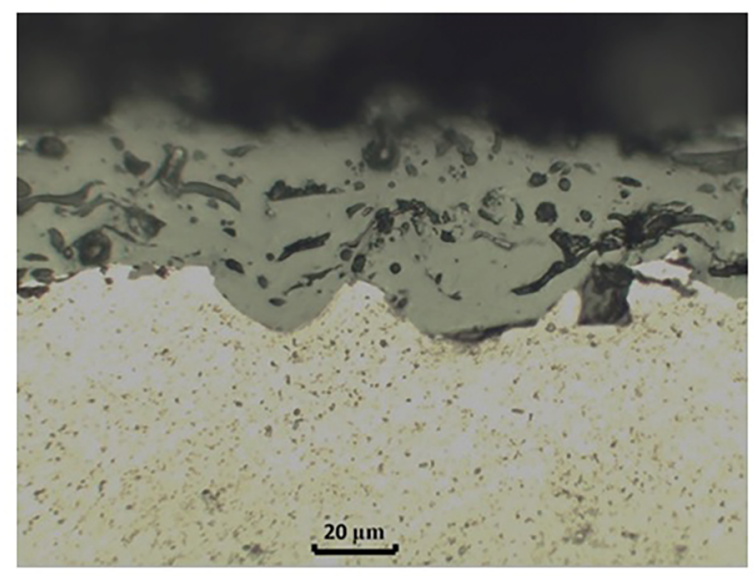

(a)

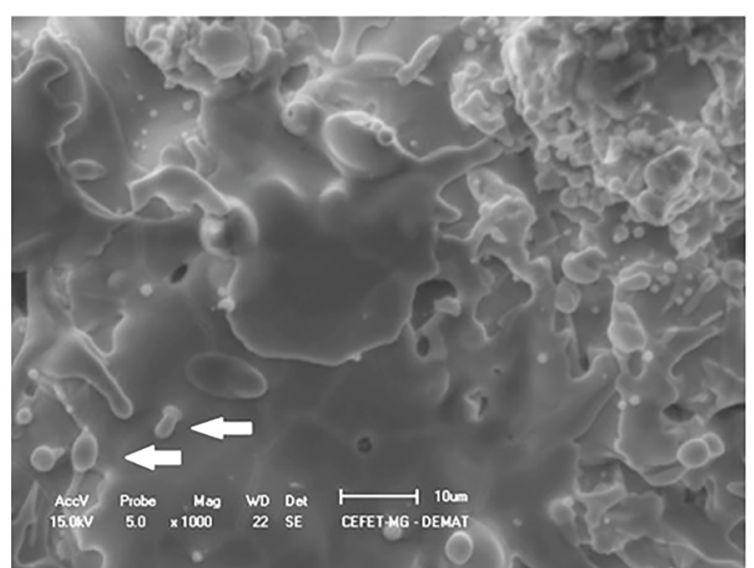

(b)

Figure 4. Micrographs of Ti-6Al-4V alloy (a) substrate/coating interaction; amorphous and crystalline $\mathrm{HAp}^{-\mathrm{TiO}_{2}}$ phases after plasma spraying (500X), without etching (optical microscopy); (b) SEM image of the morphological aspect of the coating surface with splash (white arrows), and the resulting lamellae as a result of molten projection or semi-cast droplets (1000X), without etching.

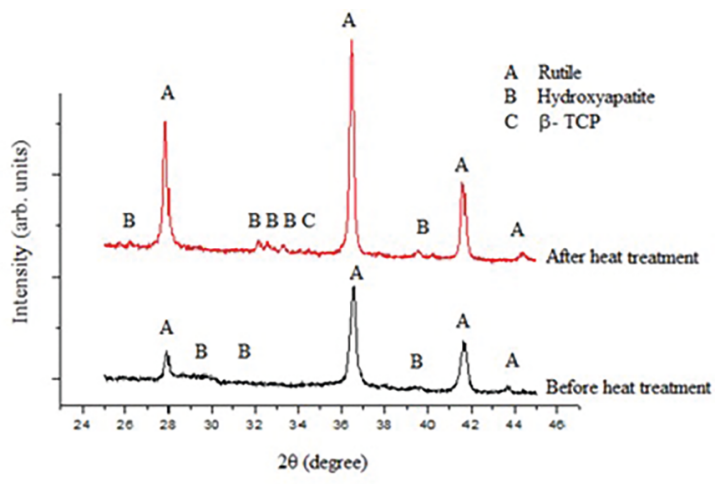

Figure 5. Diffractogram of $\mathrm{HAp}-\mathrm{TiO}_{2}$ composite showing (a) the phases before the heat treatment; (b) the phases after the heat treatment.

\subsection{Physical properties of coating}

The rough surface on Ti-6Al-4V was necessary to impart good mechanical anchoring of $\mathrm{HAp}-\mathrm{TiO}_{2}$ to the substrate. Roughness was generated by an abrasive alumina blasting process. Table 6 presents the surface roughness of the substrate and ceramic coating.
Table 6. Surface roughness of substrate and ceramic coating

\begin{tabular}{lc}
\hline Material & Roughness RA $(\mu \mathrm{m})$ \\
\hline Substrate after blasting & $4.2 \pm 0.6 \mu \mathrm{m}$ \\
Coating & $3.8 \pm 0.2 \mu \mathrm{m}$ \\
\hline
\end{tabular}

The substrate and coating roughness were similar, because the ceramic-composite deposition resulted in successive lamellar layers. Apart from promoting good mechanical coating anchoring, the substrate roughness promoted roughness in the coating. Surface roughness is known to have a significant positive influence on bone growth ${ }^{24}$.

Our results corroborate preliminary studies ${ }^{25}$; 1) An HAp coating roughness of $3.8 \pm 0.4 \mu \mathrm{m}$ was recorded for a blasted surface and $4.23 \pm 0.46 \mu \mathrm{m}$ for the coatings, 2) a $\mathrm{TiO}_{2}$ film roughness of $2.8 \pm 0.6 \mu \mathrm{m}$ was recorded for a blasted surface, and 3) $4.6 \pm 0.4 \mu \mathrm{m}$ for the coatings. All the cited authors used plasma thermal spraying for coating deposition ${ }^{26}$.

The results for coating porosity are presented in Table 7 . These values are similar to those recorded for the porosity of HAp coatings ${ }^{27}$. Lower porosity levels are a desirable 
property for coatings, because low porosity is known to minimize toxic metal ion dissolution and release from the substrate into the human body ${ }^{27}$.

Table 7. Coating porosity data.

\begin{tabular}{lc}
\hline Material & Porosity (\%) \\
\hline As deposited & $13.6 \pm 1.0$ \\
After heat treatment & $13.9 \pm 1.9$ \\
\hline
\end{tabular}

Porosity levels close to those recorded in this study have been reported in the literature. Khor et al. ${ }^{29}$ studied HAp coatings on Ti-6Al-4V alloys, and reported a coating porosity of $19 \%$. Sun et al. ${ }^{30}$ investigated the microstructure, structure, and phases of different HA coatings, and obtained coating at a porosity of up to $12 \%$. The aforementioned authors attributed this result to the low power of the plasma equipment used in the study $(27.5 \mathrm{~kW})$. The power of the equipment was increased to $42.0 \mathrm{~kW}$, which reduced the porosity level to $7 \%$. The explanation for the porosity reduction to $7 \%$ is related to the incorporation of unfused particles, which decreases the coating porosity level. A plasma power of $28.8 \mathrm{~kW}$ was used in the present study and may have contributed to the observed increase in porosity.

\subsection{Hardness}

The developed composite exhibited a hardness of $523 \pm$ $10 \mathrm{HV}_{100}$ before and $874 \pm 26 \mathrm{HV}_{100}$ after the heat treatment.
The higher hardness recorded after heat treatment is due to the enhanced crystallinity of the coating. A comparison with previous studies showed that the addition of titanium oxide to hydroxyapatite provided a significant enhancement in coating hardness, as shown in Table 8 . The authors therein used deposition variables similar to those used in the present study, including the same metallic substrate.

\subsection{Adhesion strength}

Tensile tests were performed to analyze the adhesion strength of the coating. The composite showed adhesion strength of $16.6 \pm 2.0 \mathrm{MPa}$ prior to heat treatment and $30.0 \pm 2.0 \mathrm{MPa}$ after thermal treatment. The coating herein presented better adherence than previously reported coatings which contained only hydroxyapatite. Table 9 presents the results from preliminary studies conducted over the last ten years.

A mixed fracture, indicative of adhesive failure of the coating, was observed in the non-heat-treated coatings. However, cohesive failure was also observed in the adhesive. Figure 6 (a) shows the fracture; the region representing the failed adhesive is labeled with the letter A whereas that representing cohesive failure in the coating is labeled with the letter B. A fracture showing predominantly cohesive failure in the adhesive, as well as a small region showing adhesive failure between the coating and substrate, was observed in the specimens subjected to thermal treatment. Figure 6 (b) shows the adhesive failure region marked by the letter $\mathrm{A}$.

Table 8. Hardness of $\mathrm{HAp}-\mathrm{TiO}_{2}$ compared to values reported in the literature.

\begin{tabular}{lcc}
\hline Coating material & Hardness (HV) & Reference \\
\hline HAp rich coating & 234.5 & {$[27]$} \\
$\mathrm{TiO}_{2}$ rich coating & 363.9 & {$[27]$} \\
HAp coating & 366 & {$[29]$} \\
HAp coating & 320 & {$[30]$} \\
\hline
\end{tabular}

Table 9. Adhesion strength of $\mathrm{HAp}-\mathrm{TiO}_{2}$ compared to those reported in the literature

\begin{tabular}{|c|c|c|c|}
\hline Substrate & Coating & Properties & References \\
\hline Titanium & HAp & HAp dense coating, adhesion strength $20 \mathrm{MPa}$ & {$[31]$} \\
\hline Ti-6Al-4V alloy & HAp & Adhesion strength ranging from 16 to $25 \mathrm{MPa}$ & [32] \\
\hline Ti-6Al-4V alloy & YSZ/HAp & $\begin{array}{l}\text { Hydroxyapatite stabilized through YSZ resulted in adhesion strength ranging } \\
\text { from } 23 \text { to } 30 \mathrm{MPa}\end{array}$ & [28] \\
\hline Ti-6Al-4V alloy & HAp & Coating adhesion $24.5 \mathrm{MPa}$ & {$[33]$} \\
\hline Ti-6Al-4V alloy & HAp & $\begin{array}{l}\text { Plasma spray deposition by using the C633 standard led to adhesion strength } \\
\text { ranging from } 2.1 \text { to } 9.2 \mathrm{MPa}\end{array}$ & [34] \\
\hline Ti-6Al-4V alloy & HAp & $\begin{array}{l}\text { Bonding strength varying from } 2.10 \text { to } 9.18 \mathrm{MPa} \text { with Hap sprayed on various } \\
\text { temperature substrates and by using different cooling media }\end{array}$ & {$[35]$} \\
\hline Ti-6Al-4V alloy & $\mathrm{TiO}_{2} / \mathrm{HAp}$ & $\begin{array}{l}\text { Alternating } \mathrm{TiO}_{2} \text { and } \mathrm{HA} \text { layers, with adhesion strength ranging from } 14.5 \text { to } \\
\text { 17.3 } \mathrm{MPa}\end{array}$ & {$[36]$} \\
\hline Ti-6Al-4V & HAp & Coating thickness $400 \mathrm{~mm}$, adhesion strength ranging from 12 to $16 \mathrm{MPa}$ & [8] \\
\hline
\end{tabular}




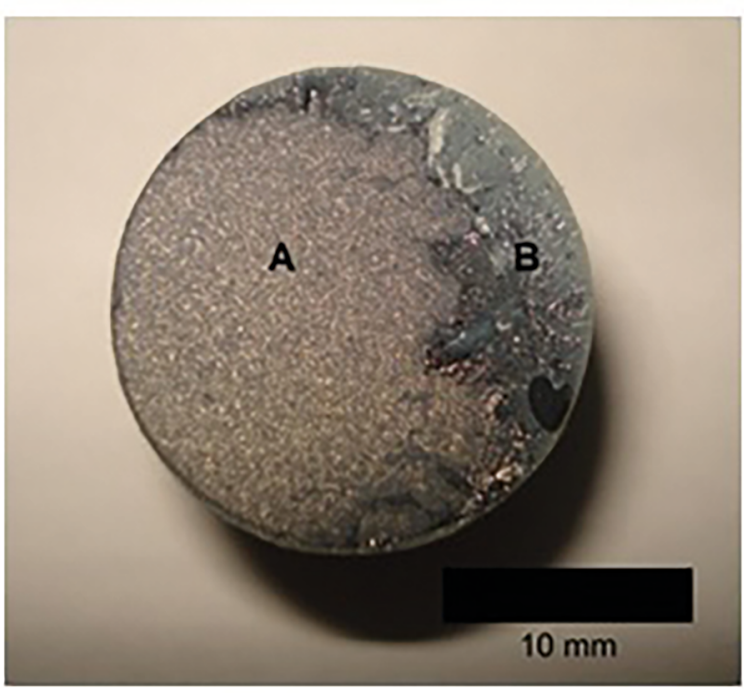

(a)

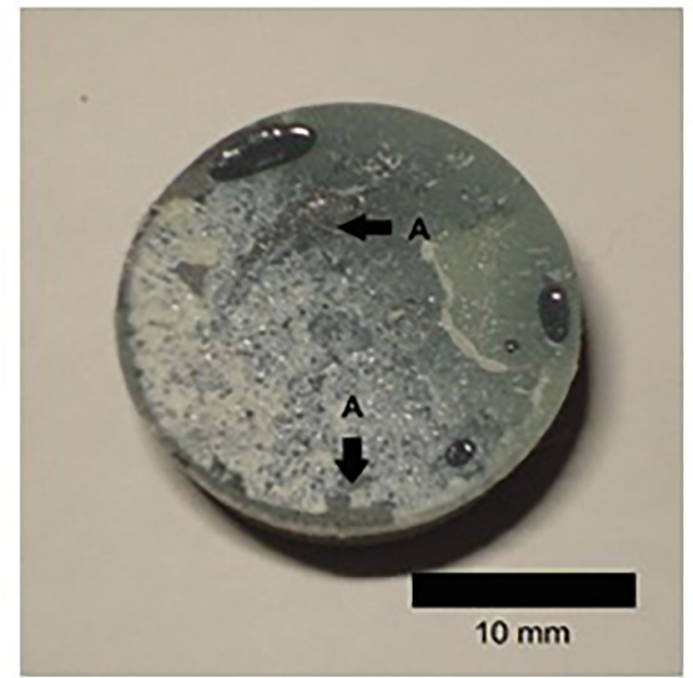

(b)

Figure 6. (a) Non-heat-treated coating after failure; (b) Heat-treated coating after failure.

\section{Conclusions}

The best range for the $\mathrm{HAp}-\mathrm{TiO}_{2}$ composition is between $47 \%$ and $57 \%$ for the addition of $\mathrm{TiO}_{2}$ to hydroxyapatite. This is so that the coefficient of linear thermal expansion of the composite is close to that of the Ti-6Al-4V alloy substrate. Thus, the $\mathrm{HAp}-\mathrm{TiO}_{2}$ composite with $50 \%$ by volume of both components was chosen because it displayed the crystalline phase of amorphous $\mathrm{TiO}_{2}$ and $\mathrm{HAp}$ after spraying. Moreover, the rutile, recrystallized hydroxyapatite and $\beta$-TCP phases after thermal treatment showed no phases resulting from the reaction between hydroxyapatite and titanium oxide. Without heat treatment, $55.6 \%$ crystallinity was observed in the as-deposited specimen, whereas $75.6 \%$ crystallinity was observed after the heat treatment. Thus, heat treatment enabled an approximately $36 \%$ increase in crystallinity in the composite. There was no significant variation in roughness and porosity, which indicates that these properties were not influenced by the heat treatment. The composite had a $\mathrm{HV}_{100}$ hardness of $874 \pm 26$ and adhesion strength of $30.0 \pm 2.0$ MPa after the heat treatment. Both these values are higher than those described in the literature.

\section{Acknowledgements}

The authors would like to thank INCT-Biofabris for the manufacture of the test specimens through rapid prototyping, to Inside Ltda. for providing the hydroxyapatite, Labiomec/ DEMA/FEM/UNICAMP for providing the titania, and CEFET-MG for the scanning electron microscope that was used in the microstructural analysis and Federal Institute of
Espirito Santo (IFES) by the financial contribution intended for the revision of the article.

\section{References}

1. Harun WSW, Asri RIM, Alias J, Zulkifli FH, Kadirgama K, Ghani SAC, Shariffuddin JHM. A comprehensive review of hydroxyapatite-based coatings adhesion on metallic biomaterials Ceramics International. 2018;44(2):1250-1268.

2. Ho WF. Effect of omega phase on mechanical properties of Ti-Mo alloys for medicals applications. Journal of Medical and Biological Engineering. 2007;28:47-51.

3. Chen Q, Thouas GA. Metallic implant biomaterials. Materials Science and Engineering. 2015;R 87:1-57.

4. Höhn S, Virtanen S. Effect of inflammatory conditions and H2O2on bare and coatedTi-6Al-4V surfaces: Corrosion behavior, metal ion release and Ca-Pformation under long-term immersion in DMEM. Applied Surface Science. 2015;357:101111. doi:10.1016/j.apsusc.2015.08.261.

5. Oliveira DP, Palmieri A, Carinci F, Bolfarini C. Gene expression of human osteoblasts cells on chemically treated surfaces of Ti-6Al-4V-ELI. Materials Science and Engineering: $C$. 2015;51:248-255. doi:10.1016/j.msec.2015.03.011.

6. Ma Z, Ren L, Liu R, Yang K, Zhang Y, Liao Z, Liu W, Qi M, Misra RDK. Effect of heat treatment on $\mathrm{Cu}$ distribution, antibacterial performance and cytotoxicity of Ti-6Al-4V-5Cu alloy. Journal of Materials Science and Technology. 2015;31:723732. doi:10.1016/j.jmst.2015.04.002.

7. Milella E, Cosentino F, Licciulli A, Massaro C. Preparation and characterisation of titania/hydroxyapatite composite coatings obtained by sol-gel process. Biomaterials. 2001;22:1425-1431. doi:10.1016/S0142-9612(00)00300-8. 
8. Rahmati B, Sarhan AAD, Zalnezhad E, Kamiab Z, Dabbagh A, Choudhury D, Abas WABW. Development of tantalum oxide (Ta-O) thin film coating on biomedical Ti-6Al-4V alloy to enhance mechanical properties and biocompatibility. Ceramics International. 2015;42:466-480. doi:10.1016/j. ceramint.2015.08.133.

9. Tsui YC, Doyle C, Clyne TW. Plasma sprayed hydroxyapatite coatings on titanium substrates. Part 1: Mechanical properties and residual stress levels. Biomaterials. 1998;19:2015-2029. doi:10.1016/S0142-9612(98)00103-3.

10. Lu YP, Li MS, Li ST, Wang ZG, Zhu RF. Plasma-sprayed hydroxyapatite+titania composite bond coat for hydroxyapatite coating on titanium substrate. Biomaterials. 2004;25:4393-4403. doi:10.1016/j.biomaterials.2003.10.092.

11. Chou B, Chang E. Interface investigation of plasma-sprayed hydroxyapatite coating on titanium alloy with $\mathrm{ZrO}_{2}$ intermediate layer as bond coat. Scripta Materialia. 2001;45:487-493.

12. Morris WF. Hydroxyapatite-coated implants: a case for their use. Journal of Oral and Maxillofacial Surgery. 1998;56:1303-1311.

13. Chalisgaonkar V, Das M, Balla VK. Laser processing of Ti composite coatings reinforced with hydroxyapatite and bioglass. Additive Manufacturing. 2018;20:134-143.

14. Li H, Khor KA, Cheang P. Thermal sprayed hydroxyapatite splats: nanostructures, pore formation mechanisms and TEM characterization. Biomaterials. 2004;25:3463-3471. Doi:10.1016/j. biomaterials.2003.10.051

15. Höhn S, Virtanen S. Biocorrosion of $\mathrm{TiO}_{2}$ nanoparticle coating of Ti-6Al-4V in DMEM under specific in vitro conditions. Applied Surface Science. 2015;329:356-362. doi:10.1016/j. apsusc.2014.12.114.

16. McPherson R. The relationship between the mechanism of formation, microstructure and properties of plasma-sprayed coatings. Thin Solid Films. 1981;83:297-310. doi:10.1016/00406090(81)90633-7.

17. Garmong G, Shepard LA. Matrix Strengthening Mechanisms of an Iron Fiber-Copper Matrix Composite as a Function of Fiber Size and Spacing. Metallurgical Transactions. 1971;2(1):175-180.

18. Lu X, Lin X, Chiumenti M, Cervera M, Li J, Ma L, Wei L, Hu Y, Huang W. Finite element analysis and experimental validation of the thermomechanical behavior in laser solid forming of Ti-6Al-4V. Additive Manufacturing. 2018;21:30-40.

19. Sheppard LM. Surge in electronic materials continues. American Ceramic Society Bulletin. 1992;70(9):1467.

20. Guo HL, Zhao XP. Preparation of a kind of red encapsulated electrophoretic ink. Optical Materials. 2004;26:297-300.

21. Castañeda L, Alonso JC, Ortiz A, Andrade E, Saniger JM, Bañuelos JG. Spray pyrolysis deposition and characterization of titanium oxide thin films. Materials Chemistry and Physics. 2002;77:938-944. doi:10.1002/crat.200710918.

22. Willmann G, Richter H, Wimmer M. Rotational bending test of hydroxyapatite plasma-coated models of Ti-6Al-4V. Biomedical Engineering/Biomedizinische Technik. 1993;38:6-14.

23. Warashina H, Sakano S, Kitamura S, Yamauchi KI, Yamaguchi J, Ishiguro N, Hasegawa Y. Biological reaction to alumina, zirconia, titanium and polyethylene particles implanted onto murine calvaria. Biomaterials. 2003;24:3655- 3661. doi: 10.1016/S0142-9612(03)00120-0.

24. Hayashi K, Inadome T, Tsurnura H, Nakashima Y, Sugioka Y. Effect of surface roughness of hydroxyapatite-coated titanium on the bone-implant interface shear strength. Biomaterials. 1994;15(14):1187-1191.

25. Braceras I, Onate JI, Goikoetxea L, Viviente JL, Alava JI, de Maeztu MA. Bone cell adhesion on ion implanted titanium alloys. Surface and Coatings Technology. 2005;196:321-326. doi:10.1016/j.surfcoat.2004.08.201.

26. Levingstone TJ, Ardhaoui M, Benyounis K, Looney L, Stokes JT. Plasma sprayed hydroxyapatite coatings: Understanding process relationships using design of experiment analysis. Surface and Coatings Technology. 2015;283:29-36.

27. Cannillo V, Lusvarghi L, Sola A. Production and characterization of plasma-sprayed $\mathrm{TiO}_{2}$-hydroxyapatite functionally graded coatings. Journal of the European Ceramic Society. 2008;28:21612169 .

28. Singh G, Singh S, Prakash S. Surface characterization of plasma sprayed pure and reinforced hydroxyapatite coating on Ti-6Al-4V alloy. Surface and Coatings Technology. 2011;205:4814-4820. doi:10.1016/j.surfcoat.2011.04.064.

29. Khor KA, Gu YW, Quek CH, Cheang P. Plasma spraying of functionally graded hydroxyapatite/Ti-6Al-4V coatings. Surface and Coatings Technology. 2003;168:195-201. doi:10.1016/ S0257-8972(03)00238-X.

30. Sun L, Berndt CC, Grey CP. Phase, structural and microstructural investigations of plasma sprayed hydroxyapatite coatings. Materials Science and Engineering: A. 2003;360:70-84. doi:10.1016/S0921-5093(03)00439-8.

31. Morks MF, Kobayashi A. Influence of spray parameters on the microstructure and mechanical properties of gas-tunnel plasma sprayed hydroxyapatite coatings. Materials Science and Engineering: B. 2007;139:209-215. doi:10.1016/j. mseb.2007.02.008.

32. Roy M, Balla VK, Bandyopadhyay A, Bose A. Compositionally graded hydroxiapatite/tricalcium phosphate coating on Ti by laser and induction plasma. Acta Biomaterialia. 2011;7:866873. doi: $10.1016 /$ j.actbio.2010.09.016

33. Gadow R, Killinger A, Stiegler N. Hydroxyapatite coatings for biomedical applications deposited by different thermal spray techniques. Surface and Coatings Technology. 2010;205:11571164. doi:10.1016/j.surfcoat.2010.03.059

34. Kweh SWK, Khor KA, Cheang P. An in vitro investigation of plasma sprayed hydroxyapatite (HA) coatings produced with flame-spheroidized feedstock. Biomaterials. 2002;23:775-785. doi: 10.1016/S0142-9612(01)00183-1.

35. Yang XYC, Chang E. Influence of residual stress on bonding strength and fracture of plasma-sprayed hydroxyapatite coatings on Ti-6Al-4V substrate. Biomaterials. 2001;22:1827-1836. doi:10.1016/S0142-9612(00)00364-1.

36. Zheng X, Huang M, Ding C. Bond strength of plasma-sprayed hydroxyapatite/Ti composite coatings. Biomaterials. 2000;21:841849. doi:10.1016/S0142-9612(99)00255-0. 